\title{
Téoros
}

Revue de recherche en tourisme

\section{Patrimoine culturel et tourisme rural}

L'exemple de la France

\section{Luc Mazuel}

Volume 20, numéro 2, été 2001

Tourisme rural

URI : https://id.erudit.org/iderudit/1071637ar

DOI : https://doi.org/10.7202/1071637ar

Aller au sommaire du numéro

Éditeur(s)

Université du Québec à Montréal

ISSN

0712-8657 (imprimé)

1923-2705 (numérique)

Découvrir la revue

Citer cet article

Mazuel, L. (2001). Patrimoine culturel et tourisme rural : l'exemple de la France. Téoros, 20(2), 7-14. https://doi.org/10.7202/1071637ar d'utilisation que vous pouvez consulter en ligne.

https://apropos.erudit.org/fr/usagers/politique-dutilisation/ 


\title{
Patrimoine culturel et tourisme rural
}

\author{
L'exemple de la France
}

\section{Luc Mazuel}

O n connaissait les potentialité de la France en matière de tourisme culturel ; elles étaient et sont encore extrêmement liées à de grands sites, connus dans le monde entier (le Louvre, Versailles, les Châteaux de la Loire), et à des clichés (la cuisine, la haute couture, un sens du raffinement). Mais la France touristique ne peut se résumer à ces quelques exemples prestigieux. Il existe une France rurale, très préservée, authentique, qui met en avant, parfois maladroitement, les atouts qui sont les siens : le petit patrimoine bâti, les sites naturels, les pratiques anciennes du monde agricole, un savoir-vivre et un savoir-faire propres à la campagne.

De nombreux pays européens connais-sent la même évolution, conditionnée par la demande du client européen désireux de «vie campagnarde». À ce titre, les Anglais et les Scandinaves ont été bien plus précoces que les Français. Cependant, la France, avec un patrimoine rural très riche et bien préservé, grâce aux politiques publiques de protection et de valorisation du patrimoine complétées par les aides de l'Union européenne, possède des atouts de poids. Malgré cet avantage, elle accumule des handicaps qui tiennent surtout à la mauvaise appréhension des marchés, des pratiques du marketing et de la communication.

Le tout premier obstacle découle du fait que l'on n'ose pas toucher à la culture, quel que soit l'objet, parce que ce pays a une tendance à sacraliser le culturel, à lui mettre un grand $« \mathrm{C} »$, rendant difficile une ap- proche purement économique qui conviendrait aujourd'hui au tourisme, activité économique à part entière.

Ensuite, si l'on devait s'en tenir aux chiffres, on pourrait douter de l'incidence du patrimoine et de la culture sur le tourisme rural français. En effet, si l'on observe les motifs des Français quant au choix des lieux de vacances sur tout le territoire, la motivation culturelle et patrimoniale ne compte que pour $12,6 \%$, la proportion tombe à $9 \%$ pour le milieu rural seul (Ministère de la Culture, 1998). Nous sommes bien loin des motivations liées au climat $(25 \%)$ ou à la famille $(23 \%)$. Malgré tout, ce choix culturel vient tout de même en troisième place.

De plus, ces chiffres ne montrent pas l'effet réel et capital du patrimoine culturel sur le tourisme rural, car la demande de culture est énorme et elle couvre des aspects qui vont bien au-delà des monuments bâtis ou des grands sites pris en compte dans ce type d'enquêtes; elle englobe des aspects divers et parfois intangibles comme la gastronomie, les traditions agricoles, les coutumes linguistiques... des éléments qui se prêtent très mal à la quantification et qui rejoignent le domaine parfois abstrait des aménités. Au-delà du patrimoine bâti, du patrimoine naturel, il faut aussi parler d'un patrimoine ethnologique, confondu aux modes de vie des habitants.

On devine alors l'extrême complexité de la «mise en tourisme» du patrimoine culturel. Nous sommes confrontés au difficile croisement de l'évolution des pratiques culturelles des occidentaux, au croisement des perceptions des locaux et des touristes, au croisement du dévelop- pement local et du tourisme. Surgissent des problèmes de déontologie où transparaît l'idée majeure de la durabilité, également des problèmes de marketing et de communication sur un thème difficile à vendre.

Pour comprendre cette situation complexe, il conviendra de rappeler l'évolution de la notion de patrimoine culturel en milieu rural ainsi que celle des liens du couple culture-tourisme. Nous pourrons alors mieux comprendre les aspects positifs, en matière de développement local par exemple, mais aussi négatifs, en matière environnementale ou éthique entre autres. Enfin, nous essaierons de mettre à jour les difficultés spécifiques du tourisme culturel rural par la confrontation des secteurs privé et public, un aspect assez particulier à la France, mais aussi de la mise sur le marché, de la médiation et de la communication.

\section{Une notion de patrimoine culturel rural revisitée}

La notion de patrimoine culturel rural est récente et, à plus forte raison, sa mise en tourisme. Des difficultés persistent pour le définir, le connaître, le préserver, le faire connaître et encore davantage le vendre. En outre, la notion est totalement évolutive, le champ du patrimoine rural s'élargissant sans cesse. Il y a sept ans, le rapport Chiva a posé, en France, les bases de toutes les réflexions sur le sujet (Ministère de la Culture, 1994a).

La définition que l'on pourrait donner aujourd'hui couvre des éléments très divers, qui vont nécessiter des approches intégrées et adaptées à chaque site. Ces 
éléments sont parfois concrets et attendus comme le patrimoine architectural, dont certains éléments prestigieux (églises, châteaux, certains éléments industriels) sont protégés par les lois ${ }^{1}$, dont les édifices modestes (fermes anciennes, fours, fontaines, croix...) sont très inégalement pris en compte.

Mais, depuis quelques années, on a compris que l'on ne pouvait considérer un bâti rural sans son environnement paysager et même animal (d'où la création des ZPPAUP ou zones de protection du patrimoine architectural urbain et paysager ${ }^{2}$ et les politiques importantes des parcs naturels). Ainsi, alors que les Anglais, les Allemands, les Suédois, les Danois en avaient acquis la certitude depuis le $\mathrm{XIX}^{\mathrm{e}}$ siècle $^{3}$, on s'intéresse à un patrimoine rural très immatériel, au-delà du couple bâtipaysage, comme les usages et les représentations qui génèrent les produits agricoles de terroir, mais aussi les objets, les rites, les danses, les langues locales, les contes et légendes et même les habitudes socioculturelles des habitants d'une micro-région.

Les services de l'État, en plus du bâti et de l'environnement, ont aujourd'hui des missions ethnologiques de récolter les savoirs, les mémoires. Ils s'en acquittent de manière très inégale selon les régions et les budgets.

Ainsi, de manière extrêmement transversale et transdisciplinaire, on s'intéresse au patrimoine culturel rural et une complémentarité - parfois une superposition hélas - des politiques de connaissance et de sauvegarde se réalise à différents niveaux territoriaux parfois sur les mêmes objets. Cette notion très élargie du patrimoine culturel rural entraîne une floraison de nouveaux écomusées, de fêtes traditionnelles, de rénovations de bâti modeste, d'actions de sauvetage de sites et d'espèces naturelles.

Cette nouvelle situation explique l'engouement du touriste, mais ce nouveau regard du touriste renforce également le mouvement. C'est un phénomène de balancier important entre une préoccupation collec- tive et une préoccupation individuelle, toutes deux centrées sur la peur de perdre ses repères dans le contexte de la mondialisation. Autant que les Anglais, parfois avec plus d'excès et un esprit nationaliste très gênant, les Français du milieu rural ont fait du patrimoine une valeur d'identification qui peut, à certains égards, être dangereuse (le régime fasciste de Vichy pendant la Seconde Guerre mondiale mettait en avant les valeurs du patrimoine campagnard et avait renforcé la sauvegarde des traditions et des bâtis régionaux).

Malgré ces évolutions, somme toute favorables, le patrimoine culturel rural disparait rapidement pour diverses raisons : désertification des campagnes après l'exode rural, abandon des bâtiments agricoles inadaptés, friches sur les paysages nonexploités, modernisation, perte des savoirfaire, manque de repères et de sensibilité des jeunes et des moins jeunes. Tous ces problèmes rendent inévitable la forte place de l'investissement public palliant les insuffisances du privé. Des actions se sont donc organisées autour de trois axes :

- l'expérimentation de méthodes de prise en compte globale du patrimoine culturel rural,

- l'organisation de réseaux de partenaires, par exemple autour des techniques d'entretien ou de la valorisation des savoir-faire,

- la diffusion, la connaissance, pour une prise de conscience des habitants et des citadins,

autant d'actions présidant à la durabilité des cultures, nécessité impérative de la durabilité du tourisme rural.

\section{Le couple culture-tourisme}

Il faut tout d'abord bien considérer que le tourisme rural ne peut, de manière monolithique, être « tout culturel ». Le séjour en milieu rural, à un moment ou à un autre, peut se charger ou s'enrichir d'un élément culturel qui n'est pas l'essentiel du séjour. D'ailleurs, le tourisme par lui-même ne peut pas cultiver, mais il suscite un éveil, un déclic, une émotion. Cependant, il existe bien, en parallèle, un tourisme culturel ru- ral exclusif, qui correspond à un segment de clientèle très motivé, très précis, représentant un marché en extension.

Plus qu'un couple tourisme-culture, il faut envisager un «ménage à trois » entre culture, tourisme et développement local durable du territoire. Les actions menées sur les plans culturel et touristique se répercutent sur la vie des habitants, sur les conditions économiques et sociales, sur l'avenir des territoires dans le respect des composantes naturelles et humaines. En ce sens, des formes de tourisme culturel de masse, en Égypte par exemple, conduisent à une menace directe sur les sites et les populations en voulant engranger trop rapidement des dividendes ; ils ont nié la dimension de durabilité.

La première condition pour unir de manière durable culture et tourisme rural, c'est de s'attacher à valoriser des atouts intrinsèques du territoire et non «parachutés». Bien sûr, un complexe touristique du type parc à thème, comme le Futuroscope de Poitiers (dans l'ouest de la France, créé de toutes pièces sur le thème de l'avenir et des technologies de pointe), peut rencontrer un énorme succès, avoir des retombées économiques importantes pour une région rurale. Cependant, l'exemple n'est pas reproductible à l'infini. Il suppose d'abord de formidables investissements y compris en infrastructures lourdes (routes, voies ferrées, hôtellerie...). On peut choisir ce concept autour de qualités propres à l'espace : c'est le cas du parc Vulcania à côté de Clermont-Ferrand (dans le Massif central) qui escompte 500000 visiteurs par an sur le thème du volcanisme dans une région de volcans et de grande richesse géologique ; l'association de techniques de pointe en salles et de sites naturels réels est ici logique.

Malgré tout, le tourisme culturel rural est un tourisme diffus, qui repose sur des petites structures, sur des sites privilégiés, très préservés, authentiques. On veillera à offrir aux visiteurs un produit qui corresponde aux réalités historiques, sociales, culturelles de la petite région et de sa population : un village de caractère, une 
tradition agricole, un savoir-faire. On n'en fera pas pour autant un supermarché de la culture. On associera plusieurs de ces éléments à des clientèles motivées. Il ne s'agit pas nécessairement d'élitisme, mais de respect, d'adéquation entre l'échelle des micro-territoires et celle des capacités d'absorption des clientèles dans le souci de la durabilité ; en un mot, de la quête de l'équilibre pour ne priver personne, sans réduire à néant les éléments constitutifs de la culture.

La mise en place d'une telle démarche peut réussir à condition de respecter trois aspects :

- La valorisation des ressources culturelles dans le cadre de partenariats et de mise en réseau (ex.: routes thématiques, coopératives, associations). Nous pouvons citer l'excellent exemple des musées des techniques et cultures comtoises dans la région Franche-Comté (est de la France), un regroupement de musées et d'industries qui font découvrir avec un seul produit et un seul passeport de découverte plusieurs sites sur le thème de l'histoire industrielle de la région.

- La démythification culturelle pour éviter l'élitisme, pour rendre le patrimoine accessible à des touristes de niveaux socioculturels et économiques différents. Il s'agit d'ouvrir la culture, en modulant les tarifs et les programmes, grâce à des approches et à des techniques de médiation et d'interprétation différentes. On peut tout aussi bien faire découvrir, à un prix raisonnable, une abbaye cistercienne à un groupe de jeunes en randonnée à partir d'une visite simple d'une journée et de l'outil informatique et, sur le même site, programmer une semaine d'activités comprenant des conférenciers de renom, une recherche personnelle en bibliothèque, des concerts classiques... pour des clientèles aisées à la recherche d'un produit $100 \%$ culturel.

- Le troisième aspect est l'attention particulière à porter à la gestion des projets : il ne faut pas s'en remettre aux seuls financements publics, mais envisager une pérennité au produit par l'initiative privée. À titre d'exemple, l'État, la

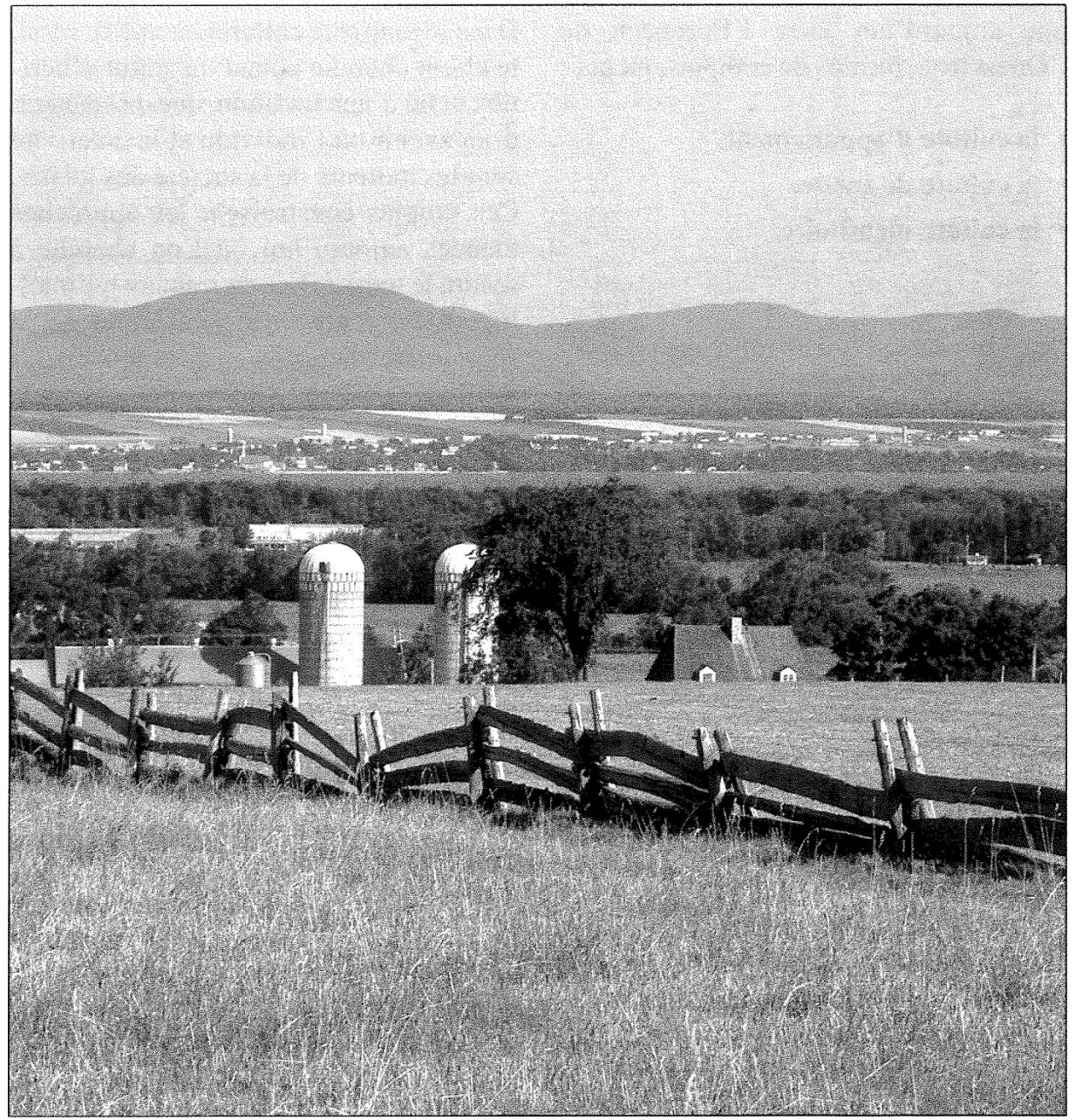

Région d'Auvergne et le département du Puy-de-Dôme viennent d'acheter le superbe domaine royal de Randan (Massif central) pour 6 millions de francs (parcs et bâtiments) et 12 millions de francs (collections d'art de la famille royale d'Orléans). Pour l'heure, aucune action privée pouvant rentabiliser ce formidable outil culturel et touristique n'est envisagée et la rénovation risque de coûter à la collectivité un minimum de 60 millions de francs, dans un premier temps !

Il conviendrait d'ajouter à ces trois aspects des corollaires. Ils supposeront en effet que les structures de gestion publiques ou privées soient attentives aux innovations (technologiques entre autres) qui changent la vision que l'on peut avoir du bien culturel, aux formations nécessaires qu'elles supposent car émergent de nouveaux métiers du tourisme culturel rural (dans le guidage en particulier), aux coopérations, à un niveau international notamment, car le patrimoine culturel s'enrichit et s'entretient dans l'échange.

Il faut rappeler que le tourisme culturel rural évolue vite car les comportements des clientèles de l'Europe de l'Ouest se modifient parallèlement dans le domaine de la consommation culturelle. Les dépenses culturelles des Français, au cours des dix dernières années, se sont multipliées par 5,5 (et seulement 3,3 pour l'ensemble de la consommation, pendant la même période) ! Il n'y a que le domaine de la santé qui ait connu une telle progression. Les ménages français ont dépensé en moyenne plus de 6000 francs par an pendant les dernières années pour la consommation culturelle.

Sur le plan de l'évolution qualitative, la forme de comportement culturel influe sur la forme du produit touristique. On distin- 
gue aujourd'hui chez l'Européen de l'Ouest trois formes de comportements :

- la culture d'appartement,

- la culture de sortie,

- la culture identitaire.

On peut avancer que le tourisme culturel est un mélange des trois, y compris dans le milieu rural. La culture d'appartement, qui inclut la télévision et l'ordinateur, implique qu'il est difficile de créer un site culturel sans faire appel à des mises en scène qui s'inspirent de ces outils ou qui en justifient l'intrusion. Nous voyons, nous jugeons, nous pensons de plus en plus par le prisme de ces médias. Nos référents culturels naissent de la «pré-digestion» qu'ils effectuent pour nous et qui nous devient nécessaire pour appréhender un objet culturel quel qu'il soit, y compris un paysage.

La culture de sortie a bien sûr une influence. Beaucoup de produits touristiques ruraux français, à proximité immédiate de tous les centres urbains du pays, peuvent se dérouler sur une ou deux journées. C'est une consommation limitée, mais festive, souvent vécue à deux par des catégories socioprofessionnelles plutôt élevées. La valeur ajoutée de ces produits peut être forte car ils intègrent des prestations de grande qualité, dont les aspects classiques de l'hébergement et de la restauration.

Mais c'est bien le modèle de la culture identitaire qui est déterminant. D'une part, de manière collective, nos sociétés occidentales tentent de retrouver dans le milieu rural des bases identitaires propres pour « affronter » l'américanisation de la culture dans le contexte de mondialisation et, de manière individuelle, on trouve le phénomène de la « construction de soi », d'affirmation de sa créativité et de sa personnalité. Après les années 1980 qui ont, dans le tourisme et dans la culture, porté des valeurs de réussite professionnelle, de culte du corps et de la technologie, les années 1990 ont consacré l'épanouissement personnel, le retour à des valeurs de simplicité, à la nature, à la tradition.
Dans le tourisme culturel en milieu rural, le client cherche autant un statut d'héritier, celui d'une tradition, que de créateur, d'un avenir où l'individu et la créativité sont les moteurs de la société des loisirs. Ces utopies construisent les approches menées aujourd'hui où 1'on cherche à rendre le touriste heureux autant qu'intelligent. Le mythe d'Antée, celui de la source, est omniprésent dans les images symboles choisies par les communicants.

\section{Des répercussions favorables sur le développement local}

Malgré de trop nombreux cas dans lesquels l'utilisation du patrimoine à des fins touristiques sert plus de faire-valoir à des élus politiques qui gaspillent les finances publiques ou encore à faire fructifier les intérêts particuliers d'une agence privée déconnectée du contexte local, on peut dire, qu'à bien des égards, les conséquences sur le développement local durable sont positives. Un patrimoine valorisé donne à une population rurale une fierté et le sentiment d'appartenir à une communauté dont le patrimoine devient l'emblème. De plus, ce patrimoine valorisé agit bien audelà du simple objectif touristique ; par exemple, un beau village rénové est aussi attractif pour des nouveaux venus (par le biais du télétravail par exemple), pour des retraités ou encore pour des artisans d'art.

\section{Tout cela suppose trois préalables :}

- la capacité d'investissement personnel et collectif des populations locales (ouverture d'esprit, conscience des objets patrimoniaux, possibilités économiques et culturelles de s'investir...) ;

- des qualités patrimoniales réelles et non supposées du territoire (car il n'y a rien de pire que la désillusion du touriste si l'on veut aller dans le sens de la durabilité) ;

- les capacités à organiser, à structurer et à gérer des acteurs qu'ils soient publics ou privés ;

Plutôt que de théoriser, nous souhaitons livrer ici l'exemple d'un petit village de notre région du Massif central français. Il n'est pas nécessairement reproductible, mais il montre le mécanisme qui a conduit une communauté d'habitants de la situation dramatique d'abandon du village à sa renaissance complète par le biais exclusif du tourisme patrimonial.

Lavaudieu est un petit village typique aux vieilles maisons de pierre qui entoure une abbaye romane du $\mathrm{XI}^{\mathrm{e}}$ siècle possédant un ensemble de peintures murales du XIII ${ }^{\mathrm{e}}$ siècle. En 1980, il n'y avait plus un seul commerce, l'école était menacée de fermeture avec seulement six élèves et le nombre d'habitants était de 220. En 1969, une association «Vallis Dei » a été créée et, avec la municipalité, elle a mené un long combat pour restaurer l'ensemble exceptionnel de fresques (un des plus importants de France). Rien n'aurait été possible si l'ensemble n'avait pas été classé « Monument Historique », l'État prenant en charge $50 \%$ des travaux (le reste provenant de la région, du département et $5 \%$ de la commune, ce qui représentait un gros sacrifice pour une commune sans moyens financiers). Persuader les habitants (surtout des agriculteurs) que cet argent était utilement dépensé s'est révélé un travail très difficile et permanent. La restauration exemplaire a conduit à une augmentation spectaculaire du nombre de visiteurs (plus de 35000 visiteurs payants en 2000 et 70000 estimés pour le passage dans le village chaque année).

Il a donc fallu qu'au-delà du monument, le village soit aménagé : enterrement des réseaux électriques, illuminations nocturnes, pavages à l'ancienne, fleurissement avec fleurs locales vivaces, création d'un point d'information en été, visites guidées, festival musical de quelques soirées en été, expositions d'art, aménagement d'un stationnement à l'entrée du village, nettoyage des rives, aire de pique-nique, signalétique... Sans l'aide de l'État (fonds FIDAR ${ }^{4}$, Monuments Historiques...), de l'Europe (Objectif 5b, LEADER, FEOGA, FEDER $^{5}$ ), de la région (Programme des cités de caractère...) et d'autres partenaires comme des mécènes, des grandes entreprises (EDF, industries pharmaceutiques), le village ne serait pas un point touristique important qui, grâce à l'activité culturelle touristique a vu la création de deux 
restaurants, d'un café, d'une chambre d'hôtes, d'une miellerie, d'un atelier de mosaïste, d'un atelier de fleurs séchées et d'un atelier-musée de renommée mondiale, le Carrefour Européen du Vitrail qui, à lui seul attire 20000 visiteurs par an). Des familles nouvelles se sont installées. Le village a gagné une trentaine d'habitants. L'école compte maintenant douze élèves. On a même associé les habitants à la création d'un musée des arts et traditions populaires où chacun a déposé un ou plusieurs objets pour constituer un lieu de mémoire collective, créateur de solidarité, de fierté locale, utile à la « réappropriation » culturelle des habitants locaux. Les prestataires jouent le partenariat avec l'association qui gère l'Abbaye et le musée. On aborde le tourisme avec professionnalisme en évitant de ne vivre que par l'accumulation opportune des financements publics. Le grand projet est aujourd'hui la création d'un centre culturel de la peinture murale pour retenir le touriste plusieurs jours (stages, conférences, ateliers...). Il faut signaler aussi que le site est maintenant classé ZPPAUP, procédure certes très contraignante, mais qui garantit le respect total du bâti dans ses moindres caractéristiques dans un système de covisibilité à partir de l'Abbaye. Enfin, le site a obtenu la mention «Un des plus beaux villages de France ${ }^{6}$ ».

Tous les villages n'ont pas les atouts esthétiques et historiques de Lavaudieu. Cependant l'exemple montre que l'on peut créer ce type d'activité en milieu très rural même si un des avantages de cet exemple est d'être situé à 20 minutes d'un axe autoroutier important et à 50 minutes d'une métropole régionale de 300000 habitants. Si le produit s'appuie sur des qualités réelles (capacités humaines ou patrimoniales), l'éloignement, le manque relatif de services n'est plus un obstacle aussi important.

Cet exemple montre comment la conjonction d'une mobilisation de la population - pourtant peu réceptive au départ - avec l'atout des financements publics et la professionnalisation des prestataires a conduit à la sauvegarde du village, à l'augmentation de sa population (phénomène exceptionnel dans cette région) et à la diversification économique dans une zone d'agriculture monolithique en déclin.

\section{Les dangers}

Si le tourisme valorise le patrimoine culturel rural, il peut aussi contribuer à son altération, voire à sa disparition. En effet, la surfréquentation d'un site, l'exploitation outrancière ou une «disneylandisation » peuvent y conduire.

\section{« Disneylandisation » et « artificialisation »}

Parce que la culture américaine et les modes de consommation particuliers qu'elle génère a, malgré tout, considérablement influencé nos manières de vivre et donc de consommer de la culture et du tourisme, la France n'a pas échappé à des phénomènes comme le parc à thème ou certaines aseptisations des traditions. Ces pratiques ne sont bien sûr pas condamnables et elles rencontrent un vif succès permettant un développement économique. Malgré tout, elles vont à l'encontre des principes de durabilité que l'on s'efforce de mettre en place en Europe autour de pratiques respectueuses des sites et des sociétés locales.

À l'Écomusée d'Alsace, un ordinateur, à l'entrée du village, indique que le troupeau de vaches passera à $16 \mathrm{~h} 34$ et que le charpentier travaillera dans son atelier de 14 à 16 heures. À la boutique, on découvre une multitude d'objets pseudo-traditionnels dont beaucoup sont fabriqués en Asie. Les maisons, certes magnifiques, ont été démontées puis remontées loin de leur site d'origine.

Bien sûr, on ne peut pas tout conserver in situ et faire vivre les villageois comme au $\mathrm{XIX}^{\mathrm{e}}$ siècle pour faire plaisir au touriste, car la tradition contient étymologiquement la notion de transmission, donc de déformation. L'authentique n'existe pas. Cependant, le danger est réel d'une aseptisation qui crée un lieu indifférencié et banal correspondant à notre idée préconçue de la campagne, une image de message publicitaire. Au Québec, les Hurons font parfois une exploitation peu regardante, parfois peu sérieuse, de leurs traditions dans des parcs à touristes. En réponse contradictoire, certains villages de tribus Micmacs ont proposé des produits touristiques ambitieux, destinés à instruire des touristes en petits groupes. On leur parle de tout, y compris du présent, on évite la folklorisation dangereuse des films de cow-boys.

Le tourisme dans des milieux fragiles, ce qui est autant le cas du milieu rural en pays développé que dans un pays en voie de développement, peut devenir « dérégulateur » et destructeur. Nombre de pays ou de régions récepteurs sont privés des bénéfices empochés par les pays émetteurs. La culture peut être pillée (au propre comme au figuré), colonisée. C'est le cas des pays de l'Indochine par rapport à l'Europe ou aux États-Unis, mais c'est aussi le cas de notre région d'Auvergne par rapport aux clientèles citadines. Les maux sont similaires et de plusieurs ordres :

- atteintes à l'environnement surtout à cause de la surfréquentation (exemple des parcours de randonneurs décapant la couche végétale en montagne),

- atteintes à la culture locale (exemple extrême de l'omniprésence de CocaCola),

- effet de la saisonnalité (cause de la précarité de l'emploi en particulier).

\section{Des réponses}

Pour éviter de tels méfaits, on peut avancer plusieurs réponses. Ce sont les musées et les sites naturels qui en ont donné l'exemple en France.

\section{Réglementation et information}

Les mesures, d'abord plus attachées à la forme qu'au fond, ont été sévères pour « imposer » aux visiteurs des « codes de bonne conduite ». Les premières consistent à contrôler les cheminements, à les canaliser. Dans de nombreux sites, on a aménagé les dates et les horaires de visite en introduisant davantage de flexibilité (exemple des visites nocturnes dans les châteaux). On a modulé les tarifs pour inciter à l'étalement des visites. On a aussi 
multiplié les points d'entrée pour éviter les attentes ou pour mieux casser les flux sur certains sites naturels.

Par exemple, au Puy Mary (Massif central), une montagne classée Grand Site National, on a aménagé au bout des quatre vallées qui y conduisent, quatre lieux de présentations et de points de départ de circuits sur quatre thématiques différentes : la géologie, la faune, la flore, les traditions. On a enfin balisé et aménagé des chemins pour éviter les incursions individuelles portant atteinte aux sols.

Évidemment, le touriste peut ne pas se plier à ce système. C'est pourquoi, en plus des mesures de ce type, il est impératif d'informer et même de former le visiteur, en lui donnant des brochures, en multipliant les panneaux explicatifs intégrés, les « points propres », etc. Approche ancienne en Scandinavie, au Canada, aux États-Unis, ces initiatives sont très difficiles à faire admettre dans les pays latins de l'Europe, marqués par l'individualisme.

Sur ce point, il reste beaucoup à faire car il est difficile de responsabiliser le visiteur sur place sans l'infantiliser, ce que les Français détestent. En fait, nous touchons là à un problème fondamental des rapports entre culture et tourisme ; il s'agit de l'éducation culturelle, écologique et citoyenne des hommes qui dépasse très largement le cadre du tourisme, une éducation qui vise, dès l'enfance, à respecter la nature, à appréhender des cultures rurales fragilisées par la modernité... En France, l'éducation artistique et culturelle des enfants est embryonnaire, dans un pays qui se vante pourtant toujours de sa richesse culturelle. C'est un vrai problème de société qui renvoie à ce constat : celui qui voyage représente l'expression la plus forte de la société dont il est issu et celui qui accueille l'expression la plus faible de la société à laquelle il appartient.

Ajoutons que les mesures pouvant être prises sur place tiennent aussi à la qualité des prestations offertes. Une vision caricaturale du patrimoine, vendu en « petits morceaux bien calibrés », n'encourage pas le visiteur à faire des efforts. Si ce dernier ressent une qualité dans l'accueil, dans les commentaires, dans la gestion optimale du nombre d'un groupe (20 est un maximum), son comportement s'adapte, se civilise, se sociabilise.

Les agriculteurs pratiquant l'accueil à la ferme trouvent des types de réponses adaptées. Pour éviter la folklorisation passéiste, ils créent une pièce-musée où ils évoquent avec des vieux documents, des outils anciens, des reconstitutions vidéo, les pratiques paysannes d'hier, puis ils dirigent le groupe de touristes sur l'exploitation moderne, montrant l'évolution, la vie et les contraintes de l'agriculteur aujourd'hui. On prend le touriste pour un adulte capable de discernement. On ne cherche pas à lui vendre à tout prix une image désuète de la campagne. Certains spectacles historiques comme celui du Puy-du-Fou en Vendée (ouest de la France) reconstituent des épisodes de la Révolution française avec costumes et décors d'époque. Malgré tout, la qualité de la reconstitution et le sérieux de la recherche historique rendent très vivant et professionnel ce qui pourrait apparaître comme du cinéma.

\section{Du rôle incontournable des pouvoirs publics à une démarche marketing}

Nous l'avons déjà mentionné, le problème de la France aujourd'hui dans ce domaine est que les pouvoirs publics, à toutes les échelles, sont à la fois les grands gestionnaires et les décideurs de la valorisation du patrimoine rural (surtout par le biais des systèmes de protection et de subvention des sauvegardes) et du tourisme rural (mainmise sur la promotion et sur les grands aménagements).

Il est très difficile de passer de cette situation d'acteur principal et incontournable à une logique d'économie privée appuyée sur les principes du marketing. En conséquence, beaucoup de sites, de manifestations touristiques, d'animations sont déficitaires et ne vivent que par la subvention. La situation évolue par le biais de plus fréquentes sociétés d'économie mixte (public-privé) dans ce domaine et par le fait que la concertation public-privé autour d'un même site ou événement est mieux coordonnée, d'où une efficacité accrue.

Il faudrait cependant accélérer le mouvement de participation et de forte reconnaissance des prestataires privés tout en conservant le système de l'intervention publique qui reste garant d'un partage financier entre les sites « pauvres » et les sites « riches » et qui permet une meilleure sauvegarde du patrimoine que ce qui se vit dans bien des pays d'Europe. Comment cependant ne pas penser à l'excellent exemple du National Trust anglais, incarnation de la capacité collective privée à gérer le patrimoine national ? En France, la Fondation du patrimoine, son équivalent, ne parvient pas à s'imposer depuis sa création il y a six ans.

S'inscrire dans une démarche marketing n'est pas simple. À la différence d'autres pays, du nord de l'Europe essentiellement, la France et les pays du Sud européen ont de grandes difficultés. Au-delà d'un sérieux problème de formation des acteurs privés et de l'omniprésence de l'État et des collectivités publiques locales et régionales, il s'avère qu' on ne sait pas donner une dimension «produit» au patrimoine. Il n'existe en France que quelques sites comme l'Écomusée d'Alsace, le Château de Villandry et quelques autres qui ont osé. Même pour ceux-là, subsiste une grande ambiguïté. L'Écomusée d'Alsace a obtenu depuis sa création plusieurs centaines de millions de francs en subventions publiques. Aujourd'hui, il est vrai qu'il accueille près de 400000 visiteurs par an et propose de 60 à 250 emplois, selon la saison, pour une recette de 70 millions de francs par an. Le parcours-spectacle « Voyage au temps des impressionnistes » à Auvers-sur-Oise, village de Van Gogh, a accueilli 550000 visiteurs en quatre ans et atteint $65 \%$ d'autofinancement, ce qui permet de penser que l'argent public a servi à quelque chose. Il est rare que ces structures vivent sans le soutien des pouvoirs publics, de la commune à l'Union européenne (ex. programme LEADER).

Jean-Michel Puydebat, conseiller en management des structures culturelles et touristiques. croit qu'il faut : 
[...] mettre en cuvre une politique de tarification différenciée comportant un forfait famille, optimiser le rendement commercial des activités dérivées (boutique, restaurant, séminaires...), créer une offre groupes, éventuellement monter son propre tour opérateur. Il faut mener de vraies campagnes de communication produit, avec des messages forts, dans des médias ciblés.

Une difficulté essentielle découle du fait que les Français ont trop sacralisé la culture et qu'ils considèrent comme méprisable la mise en marché de la culture rurale.

On raisonne trop sur le marketing de l'offre et pas assez celui de la demande. On pense qu'il suffit de créer un équipement culturel pour que le touriste vienne. Il est évident qu'il faudrait commencer à répondre aux aspirations du client. L'Irlande fait, en Europe, figure de modèle, particulièrement par son approche des marchés étrangers. On cherche à comprendre les attentes des clients par rapport à une certaine idée de la campagne irlandaise et, ensuite, on élabore des produits appuyés par des campagnes de communication ciblées, le tout correspondant aux imaginaires des touristes potentiels. Il est symptomatique de constater qu'en France les sites patrimoniaux, excepté les centres d'interprétation et les parcs thématiques, n'ont pas de responsable marketing ou de chargé de communication. On s'en remet au seul conservateur, le « gardien du temple ». Le marketing est une réponse logique autant à la demande des subventions publiques qu'à leur diminution.

La gestion mixte reste malgré tout indispensable. L'autofinancement peut difficilement atteindre les $30 \%$ et il convient d'utiliser les subventions publiques pour la conservation des sites, très coûteuse parfois (ex. : monuments historiques), et pour l'organisation de manifestations (ex. : LEADER II européen pour des fêtes thématiques). Il convient aussi d'utiliser les moyens de communication touristique des communes (Offices du tourisme), des départements (comités départementaux du tourisme), des régions (comités régionaux) et de l'État (Maison de la France).

Les nouveaux moyens de communication et en particulier l'Internet doivent permettre davantage de dialogue et de négociation commerciale directs entre l'acheteur et le vendeur. Il conviendrait de ne plus s'adresser aux forts pratiquants culturels (seulement $3 \%$ ) que l'on juge seuls susceptibles d'être intéressés.

Ce sont de nouvelles présentations, de nouveaux outils et de nouvelles conceptions qui permettent d'assurer un avenir au tourisme culturel rural. Le public, d'une exigence terrible, et les modes de consommation très évolutifs obligent à des changements rapides à la fine pointe de la technologie. Le muséographe et le metteur en scène sont les maîtres du jeu pour relancer des produits toujours concurrencés ou menacés.

Nous pouvons résumer les points, forcément incomplets, qui synthétisent la démarche marketing appliquée à la forme particulière du tourisme culturel rural :

- Bien connaître et fidéliser sa clientèle (souvent elle revient et sert à son tour de prescripteur auprès d'autres clients). On connaît bien les moyens : questionnaires de satisfaction, cartes de vœux, suivi, articles dans la presse spécialisée...

- Établir un partenariat étroit avec les institutions publiques qui, en France, ont en charge la communication touristique des territoires (figurer dans les brochures officielles, participer aux salons, aux accueils organisés de journalistes...).

- Faire une communication adaptée (utiliser des matériaux nobles et originaux sur le plan graphique pour les documents papiers, constituer des sites Internet, soigner particulièrement la communication « presse » capitale dans le tourisme culturel).

- Passer d'un amateurisme du produit touristique à une logique de producteurconcepteur-vendeur.

Si l'on ne peut monter une offre de produits suffisante quantitativement ou qua- litativement, il faut s'associer à d'autres ou passer par des agences spécialisées même si, au départ, on semble y perdre du point de vue financier. Il existe dans le sud de la France une agence, Provence Grandeur Nature, qui sert de plate-forme de vente pour des produits uniquement axés sur le patrimoine culturel rural. Elle propose, par exemple, des week-ends d'initiation à la recherche de truffes (champignon rarissime et très cher) ou des promenades contées avec des bergers, preuve que tout peut se vendre si la présentation et les aspects professionnel et éthique sont rigoureux.

Le rapport client-producteur dans ce type de tourisme est un rapport d'extrême exigence et de rigueur, plus que dans n'importe quel autre domaine touristique.

Pour lier encore davantage tourisme rural et patrimoine culturel, on aura compris qu'il est fondamental de mener une politique de protection et de valorisation à l'échelle d'un pays, correspondant à un espace historique, géographique, culturel vécu et authentique qui n'est pas forcément la petite région administrative et politique. Cet espace touristique et culturel correspond à un type de paysage, à un type de bâti, à des pratiques culturelles des habitants d'hier et d'aujourd'hui qui sont précises, uniques. Il correspond aussi à la capacité à créer et à mettre en scène des produits touristiques obéissant aux règles du marketing, capables de générer une véritable activité économique et non simplement une animation. En Europe du Nord-Ouest, ce produit correspond bien au court séjour, dans un contexte de tourisme de proximité des grands pôles urbains et d'accompagnement adaptable du touriste qui recherche une médiation et une sécurité tout en gardant une relative liberté. Il faut prendre garde à ne pas créer des parcs d'attraction de la vie et de l'histoire campagnarde. car ce n'est pas exactement ce que le touriste européen recherche.

Un hébergement de qualité dans du bâti ancien, une nourriture du terroir, un soupçon d'activité sportive pour découvrir un site, un accompagnement par un guide de 
pays qui connaît à la fois l'histoire et la vie actuelle de la région, en petits groupes, des éléments du bâti, du paysage et de la culture locale entretenus et préservés in situ, l'utilisation de techniques modernes d'interprétation, des prix et des formules modulables, tel est, rapidement tracé, le «portrait-robot» du produit de tourisme culturel durable qui peut satisfaire un client et faire vivre un prestataire.

Une telle densité de conditions et d'interactions de paramètres montre les grandes

\section{Notes}

1 Il existe en France une législation très complexe et très favorable au patrimoine bâti. Notons que :

- depuis 1913, la loi sur les monuments historiques classés ou inscrits donne droit à de gros avantages financiers sur les travaux et les impôts (environ 50000 monuments en France) ;

- depuis 1992, les ZPPAUP, zones de protection du patrimoine architectural urbain et paysager, proposent une protection maximale à un ensemble cohérent, parfois sur un grand périmètre (plus de 200 ZPPAUP)

- il faut ajouter les protections internationales du type UNESCO et une multitude d'actions de soutien aux niveaux des communes, des départements, des régions, des parcs naturels, des Pays d'Art et d'Histoire, etc.

2 Sur le patrimoine paysager, les lois nationales et européennes se superposent : grands sites classés, ZNIEFF (zones naturelles d'intérêt écologique floristique et faunistique), Natura 2000 pour l'U.E., Parcs Naturels régionaux et nationaux et une multitude de zones protégées à l'échelle locale.

3 Les grands écomusées et les musées de traditions existent dans ces pays depuis le milieu du XIX ${ }^{\mathrm{c}}$ siècle; c'est le cas de Skansen, à Stockholm (Suède).

4 FIDAR : Fonds interministériel d'aménagement et de développement rural.

5 LEADER : Liaison Entre Actions de Développement de l'Économie Rurale; FEOGA : Fonds européen d'orientation et de garantie agricole ; FEDER : Fonds européen de développement régional.

6 Seulement deux villages ont obtenu ce label dans ce département. difficultés pour parvenir à un développement approprié. Ce sont bien cependant des lois de l'offre et de la demande - que le tourisme rural français a longtemps ignorées - dont on doit tenir compte comme dans toute activité marchande, même si celle-ci est assez spécifique puisqu'on ne vend pas son passé et sa culture comme un paquet de lessive. Certains le font, en Amérique du Nord et en Europe, mais ils y perdent l'essentiel : la mémoire pour mieux préparer l'avenir.
Luc Mazuel est maître de conférence à l'École Nationale d'Ingénieurs des Travaux Agricoles (ENITA) de ClermontFerrand et membre du Centre National de Ressources du Tourisme en Espace Rural (CNRTER).

\section{Bibliographie}

ATOLS-IREST (Association Tourisme Loisirs Sorbonne) (1997), Forum sur la mise en tourisme de la culture et du patrimoine, Paris, $66 \mathrm{p}$.

Barre, Josquin (1995), Vendre le tourisme culturel, Paris, IESA/Economica.

CNRTER (Centre National de Ressources du Tourisme en Espace Rural) (1997, 1998, 1999), Actes des Universités d'été du tourisme rural, Clermont-Ferrand.

CNT (Centre national du tourisme) (1995), Économie touristique et patrimoine culturel, Paris.

École Nationale du Patrimoine (1995), Patrimoine culturel, patrimoine naturel, Paris, $\mathrm{La}$ Documentation française.

FNPNR (Fédération nationale des parcs naturels régionaux) (1997), Quand le patrimoine fait vivre les territoires, Paris, Ministère de la Culture, CNFPT.

Frier, Pierre-Laurent (1997), Droit du patrimoine culturel, Paris, Presses universitaires de France, $526 \mathrm{p}$.

Gazette officielle du tourisme (1997), Le patrimoine, vecteur du développement local, décembre, $n^{\circ} 1410$, p. 4-6.

Gazette officielle du tourisme (1999), Quel marketing pour les musées et le patrimoine? mai, $n^{\circ} 1483$, p. 2-3.

Gazette officielle du tourisme (1999), Tourisme culturel, un partenariat FNCDT/CNMHS (Fédération nationale des comités départementaux du tourisme/Caisse nationale des monuments et des sites), octobre, $\mathrm{n}^{\circ} 1508$.

Gazette officielle du tourisme (1999), « Tourisme culturel et nouvelles technologies», Tourisme et culture, février, $\mathrm{n}^{\circ} 1473$, p. 29-31.

Les Cahiers d'Espace (1994), Tourisme et culture, Paris, 256 p.
Les Cahiers d'Espace (1995), Tourisme rural : la voie du tourisme durable, Paris, 203 p.

Les Cahiers d'Espace (1997), Interprétation du patrimoine, Paris, $176 \mathrm{p}$.

Ministère de la Culture (1994a), Une politique pour le patrimoine culturel rural, Paris.

Ministère de la Culture (1994b), Le tourisme culturel, Paris.

Ministère de la Culture (1998), Chiffres-clés, statistiques de la Culture, La Documentation française, Paris.

Ministère de la Culture (1999), Faciliter l'accès au patrimoine, Lettre d'Information du Ministère de la Culture, octobre, ${ }^{\circ} 54$, p. 7-10.

Origet Du Cluzeau, Claude (1998), Le tourisme culturel, Paris, Presses universitaires de France, $126 \mathrm{p}$.

Patin, Valéry (1997), Tourisme et patrimoine en France et en Europe, Paris, La Documentation française, $173 \mathrm{p}$.

Thuriot, Fabrice (1999), Culture et territoires : les voies de la coopération, L'Harmattan, $334 \mathrm{p}$.

Wolkonitsch, Maurice (1997), Tourisme et milieux, Paris, CTHS, 165 p. 